\title{
Determination of lymphocytes surface markers in patients with thermal burns and the influence of burn size on mononuclear cell subsets
}

\author{
Kobra Z Entezami ${ }^{1 *}$, Tahere Mosavi ${ }^{1}$ \\ Received: 9 Oct 2016 \\ Published: 15 Jul 2017
}

\begin{abstract}
Background: Thermal burn injuries impair the host defence system. Hence, in the present study, we aimed at investigating the changes in the number and phenotype of peripheral blood lymphocyte populations ( $\mathrm{T}, \mathrm{B}$, and natural killer cells) and their subpopulations in patients with thermal burns and determining the relationships with different sizes of total body surface area (TBSA).

Methods: Blood samples from 67 patients, admitted to Motahary Burn Center in Tehran, with burns from 30\% to more than 70\% TBSA were collected on Days 3 and 7 postburn. Lymphocytes and their subpopulations were identified by monoclonal antibodies. The cells were analyzed using flow cytometry. The results were compared with healthy controls.

Results: In this study, 3 and 7 days after burn injury, the percentages of CD3+, CD4+ and CD8+ lymphocyte significantly decreased, CD4+/CD8+ ratios were below the normal range, and CD19+ (B cells) significantly increased. No significant difference was obtained in the mean percentage of CD16+ (NK cells) between Days 3 and 7 postburn. Patients with burns of 30\% TBSA or greater $(>70 \%)$ had a significant reduction in CD3+, CD4+ and CD8+ ( T cells) numbers up to 7 days compared with 3 days after burn injury. Patients with $30 \%$ to $>70 \%$ TBSA burn failed to show any significant changes in CD4+/CD8+ ratio as well as CD16+ (NK cells) 3 to 7 days after burn. In patients with burns more than $30 \%$ to $>70 \%$ TBSA, CD19+ (B cells) number changes were found to be complicated after 3 and 7 days.
\end{abstract}

Conclusion: The results of this study suggest that alterations of immune cell surface markers and TBSA\% can reflect postburn lymphocyte activation.

Keywords: Thermal Burn, Total Body Surface Area (TBSA\%), Lymphocytes, Flow cytometry

Copyright@ Iran University of Medical Sciences

Cite this article as: Entezami KZ, Mosavi T. Determination of lymphocytes surface markers in patients with thermal burns and the influence of burn size on mononuclear cell subsets. Med J Islam Repub Iran. 2017 (15 Jul);31:38. https://doi.org/10.14196/mjiri.31.38

\section{Introduction}

Thermal burn injuries are among the most severe forms of trauma with both local and systemic effects. Moreover, such injuries can lead to the dysfunction of the host's defence system, and thus are associated with increased risk of susceptibility to infections and death $(1,2)$.

The severity of burn injuries is measured by the total body surface area (TBSA). The normal immune defence mechanisms start to become suppressed with burns of about $25 \%$ TBSA. It is possible that some suppressive substances excreted from burned tissue are responsible for immunosuppression (3-5). The disorders of this mechanism are under the influence of an acute thermal trauma that can change the immune cell numbers during burn injuries $(1,6)$, which may affect the level of activation

Corresponding author: Dr Kobra Z Entezami, entezamirahimi@gmail.com

1. Department of Immunology, Faculty of Medicine, Iran University of Medical Sciences, Tehran, Iran. processes in the immune system (7).

However, peripheral blood lymphocytes represent the most important line of host defence against pathogenic microorganisms in humans. It is predicted that prolonged lymphocyte dysfunction will be seen among the strongest, most serious, and life-threatening infections (8); particularly, type I T-cell response are essential for the host defence against intracellular pathogens $(9,10)$.

In recent years, several experimental and clinical studies have been conducted on postburn changes of peripheral blood lymphocyte subsets (11-13). However, no explanation has proven to be wholly satisfactory. The immunology of burn injuries is an important cause of public health problems worldwide, especially in economically develop-

$\uparrow$ What is "already known" in this topic:

The immunology of burn injuries is an important cause of public health problems worldwide. In In Iran, burn injuries have yielded significant morbidity and mortality.

\section{$\rightarrow$ What this article adds:}

The burn size appears to matter, since burn of $>30 \%$ TBSA particularly would affect the lymphocyte markers. 
ing countries (14). In Iran, burn injuries yield significant morbidity and mortality $(15,16)$.

For these reasons, we aimed at determining the expression and changes in the number and phenotypes of peripheral blood mononuclear cell subsets and their markers including $\mathrm{CD}^{+}$( $\mathrm{T}$ cells), $\mathrm{CD}^{+}$( $\mathrm{T}$ helper/inducer cell $\left.\mathrm{Th}_{1}\right), \mathrm{CD}^{+}$( $\mathrm{T}$ suppressor/cytotoxic cells $\mathrm{Ts} / \mathrm{c}$ ), $\mathrm{CD}^{+} \mathrm{CD}^{+} / \mathrm{CD}^{+}{ }^{+} \mathrm{CD} 8^{+}$ratio, $\mathrm{CD} 19^{+}$(B cells), and $\mathrm{CD} 16^{+}$ (NK cells), and calculating the correlation between these cell levels and TBSA thermal burn with $30 \%->70 \%$ on Days 3 and 7 postburn in Iranian patients. This study may help establish procedures capable of reducing the frequency of burns. To the best of our knowledge this was the first immunological study related to thermal burn patients.

\section{Methods}

\section{Patients}

Peripheral blood mononuclear cells (PBMC) of 67 samples from severely burned patients (40 males and 27 females) aged 18 to 60 years, admitted to the burn center of Motahari hospital (the only referral burn hospital in Tehran, Iran), were analyzed using monoclonal antibody immunofluorescent staining and flow cytometry and were compared to healthy controls (17). Informed consent was obtained from the patients or their family members. The study protocol was approved by the ethics committee of the hospital.

We assessed TBSA of at least 30\% (range: 30\%->70\%) in both the patients and healthy controls. In most cases, the cause of burn was fire flames. All patients received the standard treatment practiced in the burn unit, which includes debridement and medication therapy. None of the patients had physical disorders before the burn accident. The patients were divided into 3 groups according to the TBSA percentage: Group 1 with $\mathrm{TBSA}=30 \%-50 \%$ $(n=29)$, Group 2 with TBSA $=50 \%-70 \%(n=23)$, and Group 3 with TBSA $=70 \%$ or more $(n=15)$.

Initially, blood samples were collected from each patient at the time of admission to the burn center. Complete blood counts (CBC) were performed by an automatched hematological instrument (coulter Co, USA), and white cell differential counts were conducted on the smears of all patients. Then, blood samples were drawn in the morning between 9:00 AM to 11:00 AM on Days 3 and 7 postburn simultaneously for hematology and flow cytometric analysis. Unfortunately, 5 patients died before the sampling was completed.

A panel of triple colour of monoclonal antibody reagents was performed by DAKO (Denmark Co) for the flow cytometric immunophenotyping of mononuclear cells and their subpopulations bearing surface markers $\left(\mathrm{CD}^{+} \mathrm{T}\right.$ cells, CD19 ${ }^{+} \mathrm{B}$ cells, $\mathrm{CD}^{+} \mathrm{CD}^{+} \mathrm{T}$ helper lymphocytes, $\mathrm{CD}^{+} \mathrm{CD}^{+}$suppressor cytotoxic lymphocytes, $\mathrm{CD}_{16} 6^{+} \mathrm{NK}$ cells) and for helper/suppressor $\mathrm{CD}^{+} \mathrm{CD}^{+} / \mathrm{CD} 3 \mathrm{CD} 8{ }^{+}$cell ratios analysis in thermal burn patients.

Antibodies: Anti-human CD4 $4^{+}$Fl.T.C (Fluorescein isothiocyanate) + anti-human $\mathrm{CD}^{+} / \mathrm{RPE}$ (Phycoerythrin) + Anti-human $\mathrm{CD}^{+} / \mathrm{RPE}+\mathrm{CY} 5$; anti- human $\mathrm{CD}^{+} 6^{+} /$FITC
+ anti-human CD19 ${ }^{+}$RPE+ anti- human CD3 ${ }^{+} / \mathrm{RPE}-\mathrm{CY} 5$. Negative control mouse IgG1/FITC + mouse IgG $_{1} / \mathrm{RPE}+$ mouse IgG/RPE- CY5, Uti-lyse, and erythrocyte lysing solution (DAKO) were all used to measure above cells.

Fresh whole blood samples $(2 \mathrm{~mL})$ were collected into sterile ethylene diamine tetra acetate (EDTA) blood collection tubes. For surface, marker staining on unstimulated lymphocytes aliquots $(100 \mu \mathrm{l})$ of well- mixed anticoagulated whole blood were added to polystyrene tubes and incubated at room temperature in the dark with the $20 \mu \mathrm{L}$ of each combination of conjugate monoclonal antibodies for each sample. After incubation, fluorescence activated cell sorter (FACS) erythrocyte lyzing solution was added. Finally, samples were washed twice and analyzed immediately using the flow cytometry system.

\section{Statistical analysis}

Data were analyzed by one-way ANOVA, mean \pm SEM, and student $t$ test using SPSS 15. Statistical significance was set at $\mathrm{p}<0.05$.

\section{Results}

Changes in the number and phenotype of lymphocytes in all patients (males and females) following thermal burn injury with TBSA $30 \%->70 \%$ were determined by flow cytometry on Days 3 and 7 postburn. Table 1 demonstrates the results of comparison between $\mathrm{T}$ lymphocyte subsets, $\mathrm{CD}^{+} / \mathrm{CD}^{+}$ratios, B lymphocytes, and NK cells markers on Days 3 and 7 postburn in burn patients and healthy controls. All results were compared with reference ranges in our previously published article (17). Burn patients showed a remarkable reduction in absolute number of $\mathrm{CD}^{+} \mathrm{T}$ lymphocytes during both 3 and 7 days following injury, which was accounted for by a decrease in both $\mathrm{CD}^{+}$and $\mathrm{CD}^{+} \mathrm{T}$ lymphocyte subsets. The differences of $\mathrm{CD}^{+} \mathrm{T}$ cells, $\mathrm{CD} 4^{+} \mathrm{Th}$, and $\mathrm{CD}^{+} \mathrm{Tc} / \mathrm{s}$ between third and seventh postburn days were significant $(p=0.001)$. No significant difference was obtained in $\mathrm{CD} 4^{+} / \mathrm{CD}^{+}$ratios in patients between the third and seventh day after the burn injury. A moderate decrease in the number of $\mathrm{CD}^{+} /$ $\mathrm{CD}^{+}$ratios was observed in the third day. Moreover, CD19+ (B cells) levels significantly increased up to 3 and 7 days postburn in the patients compared with healthy controls.

Additionally, reduced number of $\mathrm{CD} 16^{+} \mathrm{NK}$ cells on days 3 and 7 was observed following injury in patients with burns. As displayed in Table 1, no significant difference was found in CD16 ${ }^{+} \mathrm{NK}$ cells between Days 3 and 7 postburn. The mean percentage of the number of $\mathrm{CD} 16^{+}$ (NK cells) appeared to be higher on the seventh day when compared to the third day postburn. During the study period, patients with thermal burns showed a profound reduction in the mean percentage of the most mononuclear cell subsets compared to healthy participants. $\mathrm{WBC}_{\mathrm{s}}$ gradually decreased in all patients at the time of admission to the hospital and during the whole course (7 days); however, the differences were not statistically significant $(\mathrm{p}>0.05)$. 
Table 1. Peripheral blood lymphocyte subsets analysis by flow cytometry on days 3 and 7 post-burn

\begin{tabular}{|c|c|c|c|}
\hline Cell Type & Days after the burn & Percent Mean \pm SD in the Samples & $\mathrm{p}$ \\
\hline \multirow[t]{2}{*}{$\mathrm{CD}^{+} \mathrm{T}$ cell } & Third & $42.4 \pm 14.12$ & $<0.001^{*}$ \\
\hline & Seventh & $31.92 \pm 20.77$ & \\
\hline \multirow[t]{2}{*}{$\mathrm{CD} 3{ }^{+} \mathrm{CD}^{+}{ }^{+} \mathrm{T}$ cell } & Third & $21.74 \pm 8.99$ & $<0.001 *$ \\
\hline & Seventh & $16.00 \pm 11.35$ & \\
\hline \multirow[t]{2}{*}{$\mathrm{CD}^{+} \mathrm{CD}^{+} \mathrm{T}$ cell } & Third & $19.33 \pm 10.00$ & $<0.001 *$ \\
\hline & Seventh & $14.89 \pm 11.98$ & \\
\hline \multirow[t]{2}{*}{$\mathrm{CD}^{+} / \mathrm{CD}^{+}$ratio } & Third & $1.35 \pm 0.66$ & 0.180 \\
\hline & Seventh & $1.52 \pm 1.06$ & \\
\hline \multirow[t]{2}{*}{$\mathrm{CD} 19^{+} \mathrm{B}$ cell } & Third & $22.09 \pm 9.68$ & $<0.003 *$ \\
\hline & Seventh & $18.78 \pm 9.90$ & \\
\hline \multirow[t]{2}{*}{$\mathrm{CD}^{1} 6^{+} \mathrm{NK}$ cell } & Third & $11.18 \pm 7.99$ & 0.690 \\
\hline & Seventh & $13.91 \pm 13.78$ & \\
\hline
\end{tabular}

The mean levels of $\mathrm{CD}^{+}, \mathrm{CD}^{+}$and $\mathrm{CD} 8^{+}$of lymphocytes were gradually decreased in patients with TBSA of greater than $30 \%$; however, the differences were not statistically significant. We found no differences between the groups after 3 days postburn (Table 2).

On the third day postburn, patients with $30 \%$ to $50 \%$ and $50 \%$ to $70 \%$ TBSA showed a mild decrease in the proportion of $\mathrm{CD}^{+} \mathrm{CD}^{+} / \mathrm{CD} 3 \mathrm{CD}^{+}$ratio. However, the differences were not statistically significant between the 2 groups in burn size, but the levels of $\mathrm{CD}^{+} / \mathrm{CD}^{+}$ratios began to increase in patients with TBSA more than $70 \%$ (Table 2). In patients with TBSA 30\% - >70\%, 3 days after burn injury, the mean percentage of $\mathrm{CD} 19^{+}$(B cells) significantly and gradually increased when the level of cells was compared in the 3 groups according to burn size (TBSA \%). The mean percentage levels of $\mathrm{CD}^{+} 6^{+}(\mathrm{NK}$ cells) in patients with TBSA of greater than $30 \%$ to more than $70 \%$ insignificantly decreased in each group 3 days postburn.

Table 3 demonstrates the comparison of T lymphocyte subsets, B lymphocytes, and NK cell number with respect to the percentage of TBSA in burn patients on Day 7 postburn. In patients whose burn size was $30 \%->70 \%$ of TBSA, the number of CD3 T cells was significantly diminished on Day 7 postburn when compared to Day 3 postburn, although helper and suppressor $\mathrm{T}$ cell populations were decreased with respect to burn size in the 3 groups on Day 7 postburn. The differences of $\mathrm{CD}^{+}$, $\mathrm{CD}^{+}$, and $\mathrm{CD}^{+} \mathrm{T}$ cells between each group (30\% -
$>70 \%)$ of TBSA were significant $(\mathrm{p}<0.05)$ and lymphocytes numbers were lower when compared to third day postburn. The results revealed that in Day 7 of burn injury, the $\mathrm{CD}^{+} / \mathrm{CD}^{+}$ratios in patients with burn of $30 \%$ TBSA or greater $(30 \%->70 \%)$ changed insignificantly compared with Day 3 burns. There was no significant correlation between $\mathrm{CD} 19^{+}$and TBSA percentage on Days 3 and 7 postburn in patients with $30 \%$ and $50 \%$ and $50 \%$ and $70 \%$ TBSA burn (Tables 2 and 3 ).

The mean percentage of $\mathrm{CD}_{1} 9^{+} \mathrm{B}$ lymphocytes appeared to be slightly higher on Day 7 postburn with injuries affecting $30 \%$ to $50 \%$ of their TBSA when compared with Day 3 postburn. There was no significant difference in $\mathrm{CD} 19^{+} \mathrm{B}$ lymphocyte changes between the 3 groups of patients with TBSA percentage (30->70\%) on Day 7 postburn. The $\mathrm{CD}^{+} 6^{+}$(NK cells) number was higher in Group 1 with $30 \%-50 \%$ TBSA on Day 7 when compared with Group 1 on Day 3. We observed an increase in $\mathrm{CD}^{+} 6^{+}$ levels in thermal burn patients with TBSA $>70 \%$ on day 7 after the burn injury, while the levels of $\mathrm{CD} 19^{+}$and $\mathrm{CD}_{16}{ }^{+}$in those with $\mathrm{TBSA}>50 \%$ were variable. There was no significant difference in $\mathrm{CD}^{+} 6^{+}$(NK cells) levels between the 3 burn groups on Days 3 and 7. Moreover, some of the changes in lymphocyte subset percentages were complicated.

\section{Discussion}

Burn injuries are a financial burden for health care systems worldwide and are among the most common and

Table 2. Mononuclear cell subsets in thermal burn patients according to the total burned surface area percent (TBSA\%) three days following injury

\begin{tabular}{|c|c|c|c|c|}
\hline Lymphocyte subpopulations & $\begin{array}{c}\text { Group } 1(\mathrm{n}=29) \\
30-50 \% \text { TBSA }\end{array}$ & $\begin{array}{c}\text { Group } 2(\mathrm{n}=23) \\
50-70 \% \text { TBSA }\end{array}$ & $\begin{array}{c}\text { Group } 3(\mathrm{n}=15) \\
>70 \% \text { TBSA }\end{array}$ & $\mathrm{p}$ \\
\hline $\mathrm{CD}^{+} \mathrm{T}$ cell & $46.69 \pm 11.5$ & $41.05 \pm 14.63$ & $36.94 \pm 16.01$ & 0.087 \\
\hline $\mathrm{CD}^{+}{ }^{+} \mathrm{CD} 4^{+} \mathrm{T}$ cell & $23.65 \pm 8.53$ & $20.66 \pm 8.30$ & $20.03 \pm 10.63$ & 0.368 \\
\hline $\mathrm{CD}^{+} \mathrm{CD}^{+} \mathrm{T}$ cell & $22.04 \pm 10.97$ & $19.37 \pm 9.73$ & $14.59 \pm 6.96$ & 0.069 \\
\hline $\mathrm{CD}^{+} / \mathrm{CD}^{+}$Ratio & $1.34 \pm 0.73$ & $1.26 \pm 0.62$ & $1.49 \pm 0.61$ & 0.588 \\
\hline $\mathrm{CD}_{19} 9^{+} \mathrm{B}$ cell & $18.80 \pm 7.77$ & $22.01 \pm 9.05$ & $27.9 \pm 11.32$ & $0.013 *$ \\
\hline $\mathrm{CD}^{1} 6^{+} \mathrm{NK}$ cell & $12.22 \pm 9.32$ & $10.77 \pm 7.60$ & $9.97 \pm 6.11$ & 0.661 \\
\hline
\end{tabular}

Table 3. Mononuclear cell subsets in thermal burn patients according to the total burned surface area percent (TBSA \%) seven days following injury

\begin{tabular}{|c|c|c|c|c|}
\hline Lymphocyte Subpopulations & $\begin{array}{l}\text { Group1 }(\mathrm{n}=29) \\
30-50 \% \text { TBSA }\end{array}$ & $\begin{array}{l}\text { Group2 }(\mathrm{n}=23) \\
50-70 \% \text { TBSA }\end{array}$ & $\begin{array}{c}\text { Group3 }(\mathrm{n}=15) \\
>70 \% \text { TBSA }\end{array}$ & $\mathrm{p}$ \\
\hline $\mathrm{CD}^{+} \mathrm{T}$ cell & $42.58 \pm 18.28$ & $24.33 \pm 18.42$ & $15.10 \pm 16.26$ & $0.001 *$ \\
\hline $\mathrm{CD}^{+} \mathrm{CD}^{+}{ }^{+} \mathrm{T}$ cell & $20.91 \pm 10.70$ & $13.02 \pm 10.77$ & $6.71 \pm 6.13$ & $0.003 *$ \\
\hline $\mathrm{CD}^{+} / \mathrm{CD}^{+}$ratio & $1.42 \pm 0.98$ & $1.75 \pm 1.25$ & $1.22 \pm 0.48$ & 0.411 \\
\hline $\mathrm{CD}_{19} 9^{+} \mathrm{B}$ cell & $19.16 \pm 8.16$ & $19.87 \pm 12.64$ & $14.09 \pm 4.91$ & 0.401 \\
\hline $\mathrm{CD} 16^{+} \mathrm{NK}$ cell & $15.92 \pm 13.41$ & $9.54 \pm 7.85$ & $19.54 \pm 24.50$ & 0.147 \\
\hline
\end{tabular}


devastating forms of trauma. The immunological deficit following thermal burns is a serious problem because it can delay the changes in peripheral blood mononuclear cells to normal levels $(6,8,18)$.

Application technique of flow cytometry analysis of cells positively stained with monoclonal antibodies has enabled us to make a more precise documentation of changes in the mononuclear cells 3 and 7 days after injury. In our study, Days 3 and 7 postburn were selected for specimen's collection based on the reports by Deveciand et al (19). We found a positive correlation between CBC and white blood cell differential count, which was scheduled every day or as required, and lymphocytes number in these patients. We also found a reduction in the number of lymphocytes population as well as WBC, which may contribute to the impairment of general mechanisms for immunoregulation during burn shock and transition of blood to the level of self-regulation. This is the sign of immunosuppression development.

Thus, it is concluded that based on our results, most cells reflect the severity of injury on Day 7 postburn, but affect the CD4 and CD8 positive cells to a lesser extent. Moreover, the reduction of $\mathrm{CD}^{+}$cells could be a consequence of the programmed or selective death of these cells in postburn periods, a process known as apoptosis $(8,20)$. Increased numbers of $\mathrm{CD} 19^{+}$(B cells) on Day 3 could be responsible for the increase in infections in these patients. Slightly elevated CD $16^{+} \mathrm{NK}$ cell counts on Day 7 compared to Day 3, may contribute to the injury- induced failure of NK cells function occurring after burn injury. Lymphocytes immune phenotypechanges were also correlated with TBSA percentage when we compared the 3 groups of patients (Tables 2 and 3).

The results of our study were also consistent with those of other reports $(6,21)$. Regarding the immune system, all parts have been reported to be affected in burn injuries (22). Furthermore, the burn size appears to matter, as burns of $>30 \%$ TBSA particularly affect the immune system (23). These changes are either numerical or functional. Additionally, patients with TBSA $>30 \%$ showed significantly lower levels of CD3, CD4, and CD8 positive cells on Day 7 compared to Day 3 postburn injury, which was accompanied by decreased immunological activation in these patients. Our results suggest that changes in these cells should be interpreted as a marker of an ongoing infection. A change in the ratio of CD4 to CD8 positive cells after the injury is seen more commonly in those patients with TBSA $>70 \%$ on Day 7 postburn. These results were similar to those of other reports (24).

Alteration in the balance between T suppressor lymphocytes and T-helper lymphocytes and the ratio of Th- 1 to Th-2 cells appears to be an important etiological factor in the suppression of adaptive immune response following burn injury $(22,25,26)$. Furthermore, burn toxin is one of the factors that was characterized as a polymerized complex of cell membrane lipid proteins (lipid protein complex) (27). This has been shown to inhibit the proliferation of normal T-lymphocytes in response to stimulation (11, 23 ). On the other hand, nutritional deficiencies in postburn patients definitely predispose them to immune defects.
Early and specific nutritional support can lead to restoring protein synthesis and normal immune function. Researchers examined the efficacy of immune modification diets such as glutamine-enriched diets (glutamine serves as an important source of fuel for lymphocytes and macrophages) and their clinical benefits and may prevent immunologic shortcomings and death (28-30). Therefore, peripheral blood lymphocyte defects are characterized by decreased responsiveness to infection (31-33). Moreover, we and other labs have previously established that severe burns cause impairment in peripheral blood mononuclear cells and the maximal effect occurs at several days following burn injury $(18,24,25)$. The distribution of peripheral blood lymphocytes infers that significant alterations occur in $\mathrm{CD} 19^{+}$(B cells) on Day 3 postburn. Because most B cells responses are regulated or critically dependent on $\mathrm{T}$ cell help, it is not surprising that many studies have shown a variety of defects in humeral immunity after thermal injury $(7,9,34)$. The defect appeared because of a suppressor lymphocyte affecting B cell function in each group according to the percentage total body burned (TBSA).

Insignificant changes in the level of CD16 (NK cells) population may induce apoptosis or activation induced cell death in mature lymphocytes. Therefore, it has to be taken into consideration that variable changes of $\mathrm{CD} 19^{+}$ and $\mathrm{CD}_{1} 6^{+}$may contribute to the higher incidence of infection and sepsis in patients after burn injury, especially in cases with burns of $>30 \%$ TBSA $(26,32,35)$. Finally, the failure of peripheral blood lymphocytes to regulate the immune response is considered to be an important immunological and physiological consequence of major immunosuppression after thermal burn injury $(1,4,36-40)$.

\section{Conclusion}

Quantitative flow cytometry with triple colour analysis was used to determine the immune status in patients with thermal burns from $30 \%->70 \%$ TBSA up to 7 days. The results of data analysis revealed that thermal burn injury affects the number of circulating mononuclear cells (MNCs). Moreover, it was further revealed that TBSA\% can reflect postburn lymphocytes activation, early prophylactic antibiotic usage, and adequate nutritional support of patients with severe burn injuries, and it may prevent patients from normal immune function defects. Consequently, the changes of lymphocyte subsets levels after thermal injury may provide valuable information to avoid the possible future complications.

\section{Acknowledgments}

We wish to thank the Research Deputy of Iran University of Medical Sciences, which provided the grant for this study (Grant No. 239). We are most grateful for the time and patience of the burned patients who entered into this study, and for the help of Motahari Hospital and the staffs in the Hematology Department that provided the authors with the patients' samples.

\section{Conflict of Interests}

The authors declare that they have no competing interests. 


\section{References}

1. Sparkes BG. Immunological responses to thermal injury. Burns. 1997; 23:106-113.

2. Cioffi WG. What's new in burn and metabolism. J Am Coll Surg. 2001;192:241-254

3. Church D, Elsayed S, Reid O, Winston B, Lindsay R. Burn wound infections. Clin Microbiol Rev. 2006 April;19(2):403-434.

4. Schwacha MG, Chaudry IH. The cellular basis of post-burn immunosuppression: Macrophages and mediators (review). Int J Mol Med. 2002; 10: 239-243.

5. Atiyeh BS, Al.Amm CA. Immunology of burn injury-An overview. Ann Burn Fire Disaster. 2001;14(2):78-84

6. Piatkowski A, Gröger A, Pantel M, Bozkurt A, Fuchs PC, Pallua N. The extent of thermal injury affects fractions of mononuclear cells. Burn. 2009 Mar;35(2):256-63.

7. Schluter B, Konig W, Koller M, Erbs G, Muller F. Differential regulation of $\mathrm{T}$ and $\mathrm{B}$-lymphocyte activation in severely burned patients. J trauma. 1991;31(2):239-46.

8. Teodorczyk-Injeyan JA, Cembrzynska-Nowak M, Lalani S, Peters WJ, Mills GB. Immune deficiency following thermal trauma is associated with apoptotic cell death. J Clinimmunol. 1995;15(6):318-28.

9. Decker D, Schondrof M, Bidlingmaier F, Hirner A, Von Ruecker AA. Surgical stress induces a shift in the type I /type-2-T-helper cell balance, suggesting down-regulation of cell-Mediated and up- regulation of antibody-Mediated immunity commensurate to the trauma. Surgery. 1996;119:316-25.

10. Schwacha MG, Ayala A, Chaudry IH. Insights into the role of Tlymphocytes in immunopathogenic response to thermal injury. J LeukocBiol2000;67:644-50.

11. Arturson G. Forty years in burns research the postburn inflammatory response. Burns. 2000;26:599-604.

12. Heimbach D. Burn patients, then and now. Burns. 1999;25:1-2.

13. Peng D, Huag W, Ais-wang S. Clinical significance of leukocyte infiltrative response in deep wound of patient with major burns. Burns. 2006;32(8):945-950.

14. Mirmohammadi SJ, Mehrpavar AH, Kazemeini K, Mostaghaci M. Epidemiologic characteristics of occupational Burns in Yazed, Iran. Int J Prev Med. 2013 Jun;4(6):723-727.

15. Taghaddosinejad F, Sheikhazadi A, Behnoush B, Reshadati J, Sabery SH. A survey of suicide by burning in Tehran, Iran. Acta Med Iran. 2010 July-Aug;48(4):266-72.

16. Alaghehbandan R, Rossignol AM, RastegarLari A. pediatric burn injuries in Tehran, Iran. Burns. 2001;27:115-118.

17. Shahghasempour S, Gerami M, Entezami Z. Enumeration of peripheral blood lymphocyte subsets in healthy Iranian population. Arch Iran Med. 2001;4(2):80-83.

18. Entezami KZ, Khosravi A, Mousavi T, Bahar MA. Immunophenotype of peripheral blood lymphocytes following thermal injury in patients. MJIRI. 2010;24(2):96-102.

19. Deveci M, Sengezer M , Bozkurt M, Eski M, Inal A. Comparison of lymphocyte populations in cutaneous and electrical burn patients: a clinical study. Burns. 2000;26:229-232.

20. Lebedev MU, Novikova NA, Novikov VV. Apoptosis of peripheral blood mononuclear cells in the patients after a thermal trauma. Int J Immunorehab. 1999; 14:105.

21. Fazal N, Al-Ghoul W. Thermal injury -plus-sepsis contributes to a substantial deletion of intestinal mesenteric lymphnode $\mathrm{CD}^{+} \mathrm{T}$ ceall via apoptosis. Int J Biol Sci. 2007;3:392-401.

22. Lebedev MU, Ptitsina JS, Vilkov SA, Korablev SB, Novikov VV. Membrane and soluble forms of Fas (CD95) in peripheral blood lymphocytes and in serum from burns patients. Burns. 2001;27:669-673.

23. Sparkes BG. Mechanisms of immune failure in burn injury. Vaccine. 1993;11(5):504-10.

24. Rioja LF, Alonso P, de Haro J, de la Cruz J. prognostic value of the CD4/CD8 lymphocyte ratio in moderately burned patients. Burns. 1993 Jun;19(3):198-201.

25. Lederer JA, Rodrick ML, Mannick JA. The effects of injury on the adaptive immune response. Shock. 1999;11:153-159.

26. Sayed S, Bakry R, El- Shazly M, El - Oteify M, Tterzaki S, Fekry M. Effect of major burns on early and late activating markers of peripheral blood $\mathrm{T}$ lymphocytes. Ann Burns Fire Disasters. 2013;25(1):17-21.

27. Schoenenberger GA. Burn toxins isolated from mouse and human skin. Their characterization and immunotherapy effects. Monogr Al- lergy. 1975;9:72-139.

28. Garrel D, Patenaude J, Nedelec B, Samson L, Dorais J, Champoux J, et al. Decreased mortality and infectious morbidity in adult burn patiens given enteral glutamine supplements: a prospective, controlled, randomized clinical Trial. Crit Care Med. 2003;31:2444-2449.

29. Fan J, WU J, Wu LD, Li GP, Xiong M, Chen X, et al. Effect of parenteral glutamine supplementation combined with enteral nutrition on HsP90 expression and lymphoid organ apoptosis in severely burned rats. Burns. 2016 Nov;42(7):1494-1506.

30. Mandell SP, Gibran NS. Early Enteral Nutrition for Burn injury. Adv wound care. 2014 Jan 1;3(1):64-70.

31. Kovalenko AM. Body support Role Nutritional Victims with Burn Injuries in the Stage Septiotoxemia. Klinkhir. 2015 Jun;(6):55-8.

32. Grogan JB. Altered neutrophil phagocytic function in burn patients. J trauma. 1976;16:734-738

33. Johansson J, Sjögren F, Bodelsson M, Sjoberg F. Dynamics of leukocyte receptors after severe burns: an exploratory study. Burns. 2011 Mar;37(2):227-33.

34. Schneider DF, Glenn CH, Faunce DE. Innate lymphocyte subsets and their immunoregulatory roles in burn injury and sepsis: A review J Burn Care Res. 2007;28(3):365-379.

35. Chalya PL, S Sentongo R, kakande I. HIV seroprevalence and its effect on outcome of moderate to severe burn injuries: A Ugandan experience. J Trauma Manag Outcomes. 2011 Jun 9;5(1):8 .

36. Ortiz-Prado E, Armijos L, lturralde AL. A Population -based study of the epidemiology of acute adult burns in Ecuador from 2005 to 2014. Burns. 2015 May;41(3):582-9.

37. Molloy RG, Nestor M, Collins KH, Holzheimer RG, Mannick JA, Rodrick ML. The humoral immune response after thermal injury: an experimental model. Surgery. 1994;115(3):341-8.

38. Barrow RE, Spies M, Barrow LN, Herndon DN. Influence survival benefit conferred by topical antimicrobial preparations in burn patients: a historical perspective. J Trauma. 2004; 56:863-866.

39. Posluszny JrJA, Gamlli RL. Anemia of thermal injury: Combined Acute Blood lose Anemia and Anemia of Critical illness. J Burn Care Res. 2010 Mar-Apr;31(2):229-242.

40. Stockton KA, Davis MJ, Brown MG, Boot SR, Paratz JD. Physiological responses to maximal exercise testing and the modified incremental shuttle walk test in adults after thermal injury: A pilot study. $\mathrm{J}$ Burn Care Res. 2012 Mar-Apr;33(2):252-8. 